\title{
The Reign of EVs? An economic analysis from user's perspective
}

\author{
Raul Martinez Oviedo, Zhong Fan, Sedat Gormus, Parag Kulkarni
}

Traditionally, petroleum (oil) has been the main source of energy for the US national economy and transportation sector. From all the energy required by the US in 2010, $83 \%$ was provided by fossil fuel sources. The energy use in this country is destined to four broad sectors: transportation, residential, commercial, and industrial. The transportation sector accounts for $28 \%$ of the total energy demand, and $96 \%$ of the energy used in this particular sector comes from fossil fuel. In order to satisfy these energy requirements, the US needs to import on average $337,143 \mathrm{Mbbl}^{1}$ of crude oil and petroleum products per month. Nearly $70 \%$ of the imported oil is allocated to the transportation sector to satisfy the fuel demand of cars, trucks, airplanes and marine-transport. Figure 1 shows the petroleum flow in the US in million barrels per day. The high US dependency on foreign oil, together with the continually increasing price of oil and its derivatives, has encouraged the national policy of reducing oil dependency by promoting carbon fuel (gasoline) displacement in the transport sector.

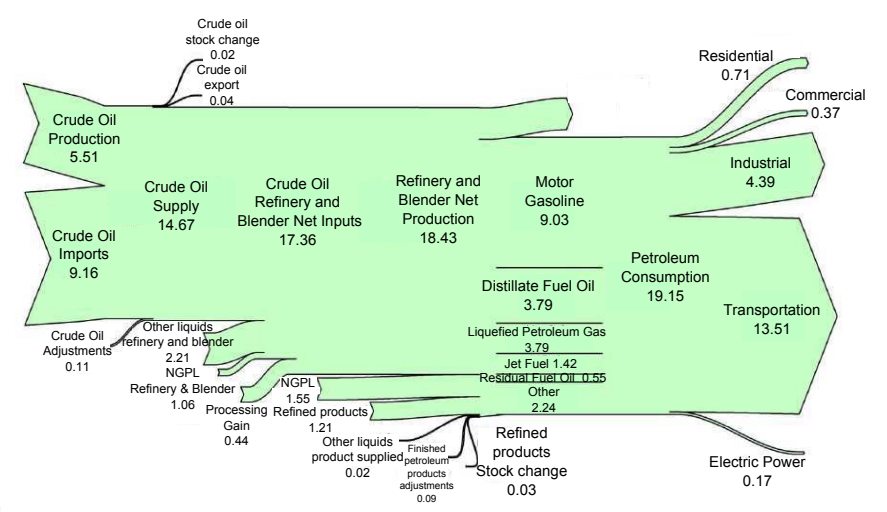

Figure 1: Petroleum flow in the US in 2010 (million barrels per day). Source: US Energy Information Administration (EIA)

In addition to the petroleum-economic concerns, there are environmental issues to consider. According to the US Environmental Protection Agency (EPA), the US transport sector emitted 2,098 million metric tons of greenhouse gases (GHG) (95\% of GHG is $\mathrm{CO}_{2}$ ) in 2006, see Figure 2. This has a significant impact in the global context since it accounts for $33 \%$ of the global transportation $\mathrm{CO}_{2}$ emissions and 7-8\% of global total GHG emissions. The majority of emissions within the transport sector are produced by light weight vehicles (cars, SUVs, and pick-ups) representing $58.7 \%$ out of the total. Thus reducing GHG emissions in these vehicles would significantly contribute to the environment at a global level.

These two arguments present a clear motivation to introduce Electrical Vehicles (EVs) and to promote their adoption among drivers. EVs, in the form of Plug-in Hybrid Electric Vehicles (PHEVs) or Battery Electric Vehicles (BEVs), offer significant benefits in improving energy efficiency, reducing emissions of pollutant and greenhouse

\footnotetext{
${ }^{1}$ based on records for 2011 and $2012(1 \mathrm{Mbbl}=1,000$ oil barrels $)$
} 


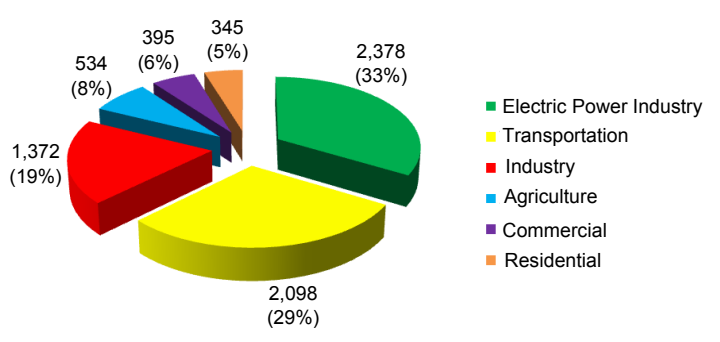

(a) Million metric tons $\mathrm{CO}_{2}$ by sector

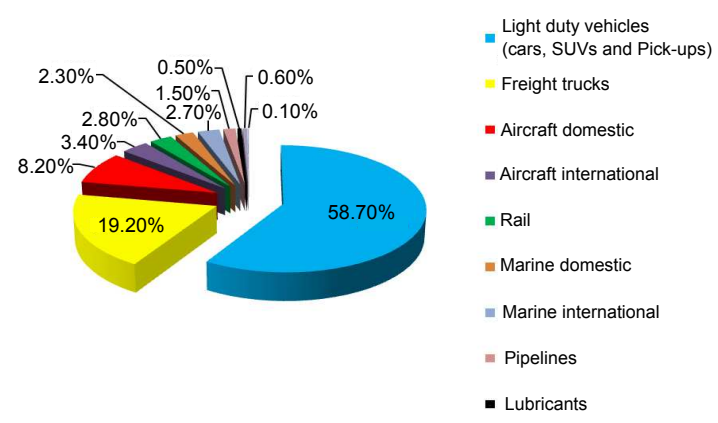

(b) Emissions by transportation mode

Figure 2: US Greenhouse gas emissions in 2006. Source: US Department of Transportation

gases, and reducing the petroleum dependency when compared with Conventional Vehicles (CVs). However, a challenging question remains: how economically attractive are EVs from a user's perspective? The main challenge limiting adoption of EVs is their current high purchasing cost. The cost of the electric battery in these cars accounts for $35-45 \%$ of the total cost of manufacturing the car, depending on the battery's size. Current battery cost ranges from $\$ 600$ to $\$ 1,000$ per kilowatt hour, and are expected to reduce to as low as $\$ 400-500 / \mathrm{kWh}$ by late 2012 or early 2013. This makes the current EV cost to be as high as double that of a CV. At the same time, it has been reported that energy cost of driving EVs is lower than that of driving CVs. This has motivated us to conduct an economic analysis to determine whether economic savings and environmental benefits offered by EVs are enough to recover the incremental premium of an EV relative to a CV within a reasonable time to represent an attractive option for users.

In this paper we conduct an economic evaluation of PHEVs and BEVs compared with CVs considering dynamic electricity pricing schemes in our analysis. Our comparative study is based on real EV models currently found in the vehicle market, and we present a case study considering California as the geographic location. The main contributions of this article can be summarized as follow:

1. We consider the impact of dynamic electricity pricing schemes in the analysis. Dynamic pricing schemes, such as Time-of-Use (TOU) and Real Time Pricing (RTP), are expected to be commonly implemented by utilities as part of Demand Response (DR) strategies in future electric grids (Smart Grids). Thus, considering their impact on economic analysis of EVs is relevant, although very few studies in the literature have considered it.

2. We present a case study for adoption of EVs in California. We analyze multiple scenarios considering fuel price trends, different electricity prices and pricing schemes, and different vehicle types. All based on real data collected in California.

3. We consider the full vehicle's life-cycle analysis (well-to-wheel) in our environmental impact evaluation of EVs and CVs. Real environmental benefits of EVs in terms of greenhouse and pollutant gases emissions reduction is relative to the energy generation mix of the region evaluated. Thus, an accurate environmental impact analysis should not only consider tailpipe $\mathrm{CO}_{2}$ emissions, but also well-to-wheel emissions. 


\subsection{Assumptions}

Our economic evaluation of EVs is subjected to the following assumptions:

1. Our economic evaluation of EVs has not considered the cost of maintenance for the vehicles studied. Literature regarding EVs suggests maintenance costs of EVs tend to be lower compared with CVs, provided that the battery unit of EVs does not require replacement during the life-time of the vehicle. If the electrical battery in an EV must be replaced, the total cost of ownership will dramatically increase. Thus, EVs would unlikely become attractive for users.

2. We have assumed a constant annual inflation rate of $2.5 \%$ in the US. Real values may change every year, traditionally fluctuating between $1.0 \%$ and $3.5 \%$.

3. Driving patterns are based on in-city driving during working days. Long trip journeys (longer than 100 miles) in highways have not been considered.

\subsection{Terminology}

Following is a definition of some of the terms used throughout the article.

- Electric Vehicles (EVs). Refers to a drive vehicle that uses an electric motor for propulsion. In the context of our work we classified EVs into two types, Plug-in Hybrid Electric Vehicles (PHEVs) and Battery Electric Vehicles (BEVs).

- Plug-in Hybrid Electric Vehicles (PHEVs). This refers to a hybrid electric vehicle that contains a battery storage system to power the vehicle, means of recharging the battery from an external source of electricity, and the ability to drive in all electric mode without consuming gasoline. A PHEV also has an internal combustion engine (ICE) that allows the vehicle to commute using a gasoline powered engine once the battery has depleted. The common notation to describe PHEVs is " $P H E V_{x}$ ", where the term $x$ refers to the distance range (in miles) the vehicle is expected to drive in electric mode.

- Battery Electric Vehicle (BEV). BEVs are vehicles fully powered by electric battery without any ICE. These vehicles do not rely on petroleum derivatives for propulsion. Batteries can be normally recharged or switched to extend the driving range.

- Carbon intensity. The carbon intensity of a power generation mix refers to the intensity of $\mathrm{CO}_{2}$ emissions resulting from the electricity generation. It is normally quantified as the number of grams of $\mathrm{CO}_{2}$ emitted per $\mathrm{kWh}$ generated. Carbon intensity depends on the characteristics of the energy sources used in the power generation mix. Cleaner sources, with low coal or petroleum components, present lower carbon intensity than those using a high fraction of carbon energy sources. 
- Well-to-wheels. Term used in the automotive life-cycle analysis that includes energy companies (oil or electricity) activities and all the operations of converting the energy from their raw sources to the form of fuel or electricity to be provided to the tanks or batteries of the vehicles to drive. This assessment is used to study the energy use or green house gas emissions.

- Time-of-Use (TOU). Electricity pricing scheme in which the price of the electricity varies in different hours of the day grouped into bands according to peak, mid-peak and off-peak periods. The distinction of peak, mid-peak, and off-peak hours is based on the load profile maintained by the energy supplier. In TOU pricing scheme, prices can change twice a year to reflect seasonal demand variations.

- Real Time Pricing (RTP). It is a dynamic pricing scheme in which electricity price varies hourly or sub-hourly all year long. Price variation reflects the utility's cost of generating and purchasing electricity at the wholesale level.

\subsection{Case study: California, US}

\subsubsection{Vehicle considerations}

For our economic evaluation we have considered a total of four vehicles classified as compact cars of similar characteristics and sizes. This includes a $\mathrm{PHEV}_{40}$ based on the specification given for the Chevrolet Volt 2012, a PHEV 14.3 based on the specifications given for the Toyota Prius 2012, an EV based on the characteristic of the Nissan Leaf 2012, and a CV based on the specifications provided for a Toyota Corolla 2012. These particular models were selected since they represent a popular option in their respective category in the current vehicle market, and they have been broadly used as models of reference in the literature.

The Chevrolet Volt is a hybrid sedan that combines electric and gasoline powered engine, with a typical electrical range of 40 miles. The vehicle has a Lithium-ion battery with a maximum capacity of $16 \mathrm{kWh}$ that can be recharged by plugging it into the grid at $110 \mathrm{~V}$ or $240 \mathrm{~V}$. The charging time depends on the initial state of charge, taking normally between 4 to 6 hours to be fully charged. The retail cost of this vehicle is $\$ 31,645$. The Toyota Prius is also a PHEV with an electric range of 14.3 miles. It has a Lithium-ion battery with a maximum capacity of 4.4 $\mathrm{kWh}$ that can be charged in 3 hours at $120 \mathrm{~V}$ or 1.5 hours at $240 \mathrm{~V}$. The price of the Toyota Prius in the US is $\$ 32,000$. The Nissan Leaf is a fully electric powered vehicle with a $24 \mathrm{kWh}$ Litium-ion battery. The battery can be fully recharged in 8 hours at 240V. The price of the Nissan Leaf in the US is $\$ 35,200$. The Toyota Corolla is a CV powered completely by an ICE of 1.8 Litre and four cylinders. It has a fuel economy of $26 \mathrm{mpg}$ in city and can be purchased for $\$ 17,000$ in the US market. Table 1 summarizes the specifications for these vehicles provided on their website.

A main consideration of EVs (PHEVs and BEVs) regards the difference in cost compared to CVs. Currently EVs 
Table 1: Vehicles specifications and cost

\begin{tabular}{|c|c|c|c|c|}
\hline & $\begin{array}{l}\text { Chevy Volt } \\
\left(\mathrm{PHEV}_{40}\right)\end{array}$ & $\begin{array}{l}\text { Toyota Prius } \\
\left(\mathrm{PHEV}_{14.3}\right) \\
\end{array}$ & $\begin{array}{c}\text { Nissan Leaf } \\
(\mathrm{BEV})\end{array}$ & $\begin{array}{c}\text { Toyota Corolla } \\
(\mathrm{CV})\end{array}$ \\
\hline Battery capacity & $16 \mathrm{kWh}$ & $4.4 \mathrm{kWh}$ & $24 \mathrm{kWh}$ & - \\
\hline Charging time & $4 \mathrm{~h} @ 240 \mathrm{~V}$ & $3 \mathrm{~h} @ 120 \mathrm{~V}$ & $8 \mathrm{~h} @ 240 \mathrm{~V}$ & - \\
\hline Max. charging energy & $3.3 \mathrm{kWh}$ & $1.47 \mathrm{kWh}$ & $3.3 \mathrm{kWh}$ & - \\
\hline Electric range & 40 miles & 14.3 miles & 100 miles & - \\
\hline Electric economy & 2.5 miles $/ \mathrm{kWh}$ & 3.3 miles $/ \mathrm{kWh}$ & 4.2 miles $/ \mathrm{kWh}$ & - \\
\hline Gasoline economy (city) & $35 \mathrm{mpg}$ & $51 \mathrm{mpg}$ & - & $26 \mathrm{mpg}$ \\
\hline Retail cost & $\$ 31,645$ & $\$ 32,000$ & $\$ 35,200$ & $\$ 17,000$ \\
\hline Tailpipe emissions & $240 \mathrm{gCO}_{2} / \mathrm{mile}$ & $133 \mathrm{gCO}_{2} / \mathrm{mile}$ & $0 \mathrm{gCO}_{2} / \mathrm{mile}$ & $306 \mathrm{gCO}_{2} / \mathrm{mile}$ \\
\hline EPA smog score & 6 & 9 & 10 & 6 \\
\hline
\end{tabular}

can cost as much as double the price of a CV. The reason for this relies on the high cost of the electric technology, particularly the battery system.

\subsubsection{Electricity generation mix and pricing schemes}

California's electricity in-state generation reached a total of 200,414 GWh in 2011 to satisfy $71 \%$ of the state electricity demand. Figure 3 shows the fuel sources for electric power generation used by electric companies in California to generate electricity.

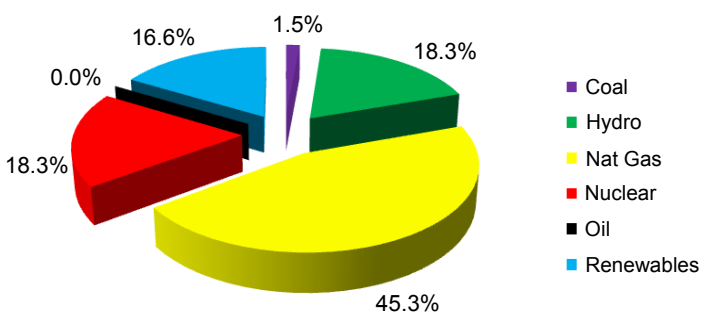

Figure 3: Fuel source for electric power generation in California in 2011. Source: The California Energy Commission

The environmental impacts of electricity generation in power plants highly depends on the characteristics of the power generation mix used. In those generation mix scenarios in which high-carbon fuels, such as coal and oil, are the main source of energy; the carbon-intensity increases deriving in a higher well-to-wheel greenhouse gas emission (mainly $\mathrm{CO}_{2}$ ) per $\mathrm{kWh}$ generated. In this sense, the source of energy used in the power generation mix makes California's electricity generation to be among the cleanest in the US due to a high contribution of carbon-free energy technologies (natural gas, nuclear, hydro, and renewables) combined with a low component of coal. This has led to an estimated $\mathrm{CO}_{2}$ intensity of 273 grammes per $\mathrm{kWh}\left(\mathrm{gCO}_{2} / \mathrm{kWh}\right)$ overall for this state. In Indiana, where the generation mix heavily relies on coal (69\% in 2011) its $\mathrm{CO}_{2}$ emissions per unit of electricity are $937 \mathrm{gCO}_{2} / \mathrm{kWh}$ The US national average is $620 \mathrm{gCO}_{2} / \mathrm{kWh}$, while the current carbon-intensity for the European electric sector is $410 \mathrm{gCO}_{2} / \mathrm{kWh}$. 
Electricity prices for the residential sector in California vary according to the utility company that provides the service. Currently, Pacific Gas \& Electric Company (PG\&E) provides the electricity for the majority of the state including Los Angeles, San Jose, San Francisco, and other major cities. The price offered by this utility is around $\$ 0.220 / \mathrm{kWh}$, which is nearly double that in the rest of the state, and $63 \%$ higher than the average of the US. For the purpose of our study we have considered three types of pricing schemes: Time of Use (TOU), Real Time Pricing (RTP) and flat rate pricing. The tariff and periods considered for each scheme are based on the information provided by PG\&E and ComEd and they are illustrated in Figure 4.

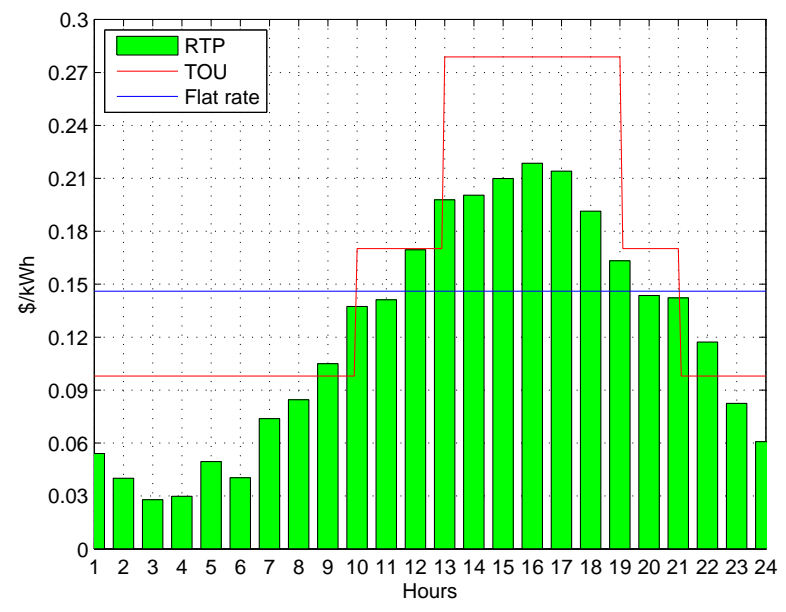

Figure 4: TOU, RTP and flat rate pricing schemes

Variations of the electricity price in California has remained small in the past 20 years since electricity generation is not a volatile market. Figure 5 shows the electricity price given by three major utilities in California since 1980 . As can be seen from the figure differences in price are little throughout the years. Assuming this characteristic will continue for the next 20 years, we have considered the TOU and fixed pricing tariffs to remain constant in time independently of seasons. In case of the RTP scheme, prices vary per hour and are assumed to be forecasted a day in advance. However, variations in each hour time slot are kept around a constant range.

\subsubsection{Gasoline price}

On the contrary to the electricity market, the oil and gasoline market is characterized for being highly dynamic and volatile. Price of gasoline varies daily and the current price is constantly affected by globally economical, social, and political events. This affects gasoline prices significantly in relatively short time periods. In California, the price of gasoline has sustained an increasing trend in the last decade with some temporal drops as shown in Figure 6(a). The current gasoline price in this state varies between $\$ 3.761$ to $\$ 4.251$ per gallon (1 gallon $=3.785$ litres).

Based on this information, for the purpose of our economic analysis we have defined three different scenarios to project the price of gasoline for the following ten years. The first scenario assumes the gasoline price will continue 


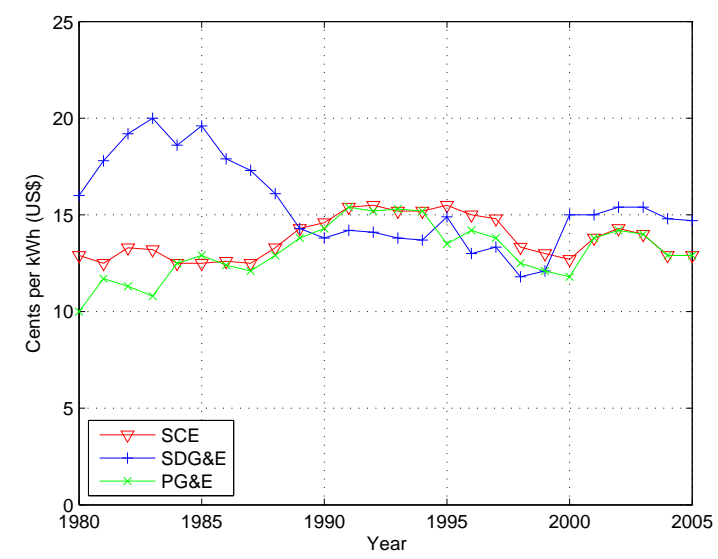

Figure 5: Electricity price for three major utilities in California. Source: California Energy Commission
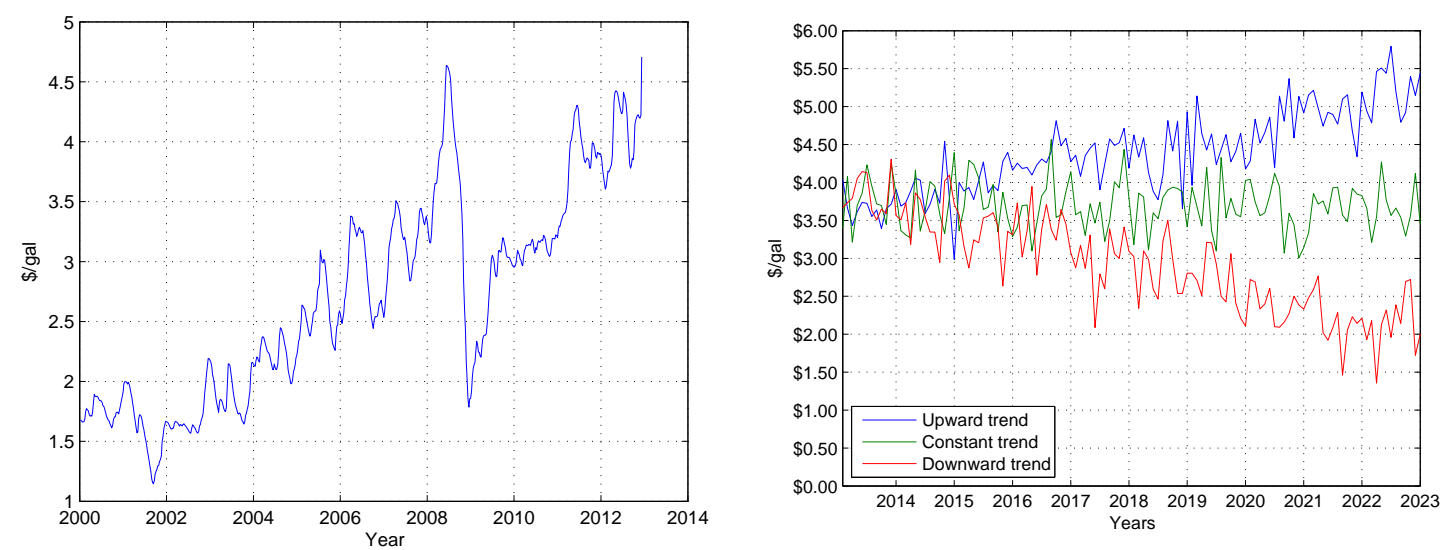

(a) Retail gasoline prices in the last decade. Source: US (b) Scenarios for the gasoline price projection in the followEnergy Information Administration ing decade

Figure 6: California all formulation retail gasoline prices

increasing and it sets an upward trend to reach the order of $\$ 5$ to $\$ 6$ per gallon by 2023 . The second scenario establishes a flat trend around the current gasoline price. And finally the third scenario assumes gasoline price will drop as low as $\$ 2.5$ per gallon by 2023 . In each scenario the daily gasoline price is randomly generated to represent the uncertainty involved in the real gasoline/oil market. This is shown in Figure 6(b).

\subsubsection{Drive cycle}

The California Department of Transportation provides detailed information about the socioeconomic characteristics and travel behavior of vehicle holders statewide. The information is normally available in the California Household Travel Survey. However, we haven't been able to find specific information about the daily travel distance distribution in California. Instead, other references provide statistics about distance driving patterns based on real world GPS data interpretation collected in different metropolitan areas in the US that can be easily generalized to represent any urban area in the country. 
In our work, we have assumed the average daily driving distance is modeled based on measurements conducted by US Environmental Protection Agency (EPA) from more than 100 drivers in Kansas City in 2005, and the information provided by the National Household Travel Survey (NHTS). The distribution is illustrated in Figure 7. From the figure it can be deducted that fifty percent of the drivers drive more than 40 miles per day, with a mean of 37.3 miles daily.

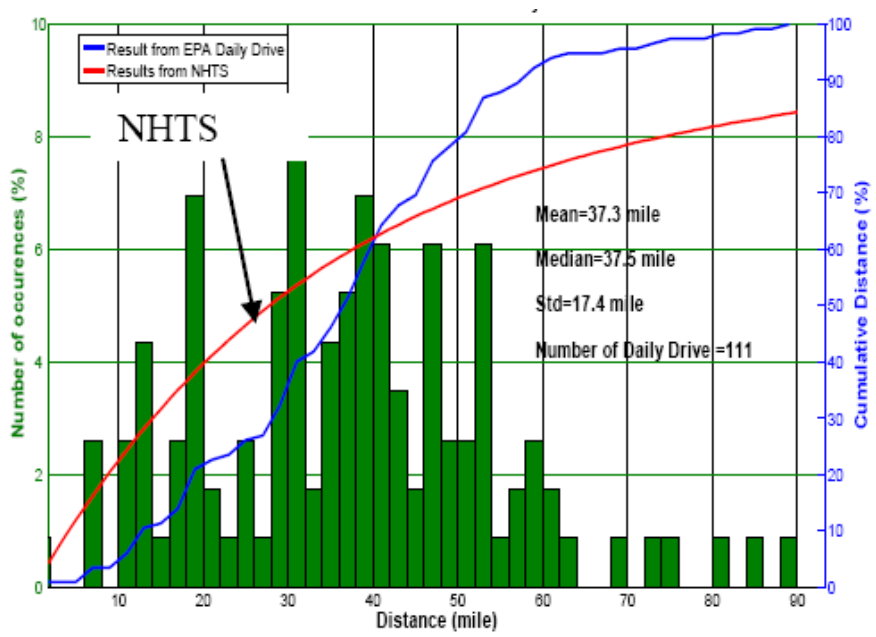

Figure 7: Daily driving distance distribution

\subsection{Results}

Monte Carlo simulations were conducted to perform a comparative economic study among different kind of vehicles: PHEV, BEV and CV. Multiple evaluation scenarios were considered based on a combination of different fuel price trends and electricity pricing schemes.

\subsubsection{Cumulative cost and gasoline displacement}

The cumulative cost evaluation considers the cost incurred in terms of the energy required to power the vehicle. This includes cost in fuel and electricity, where appropriate, throughout time. Figure 8 shows the cumulative cost as a function of years after purchasing the vehicle for three scenarios: when assuming (a) an upward trend, (b) a flat trend and (c) a downward trend in price of gasoline. In all cases, a fixed flat rate of $\$ 0.1460 / \mathrm{kWh}$ for the electricity price has been assumed. From the figures it is seen that EVs (PHEVs and BEVs) have cheaper cost of energy compared to a CV for scenarios (a) and (b). However, the current difference in the initial retail price of the vehicle renders a CV more expensive subsequent to 11 years and 15 years after purchase respectively. In the scenario in which the price of fuel tends to decrease, a CV will always be a cheaper option compared with any EV and the expenses in fuel would not surpass the cumulative cost of an EV. It was also found that for the increasing 


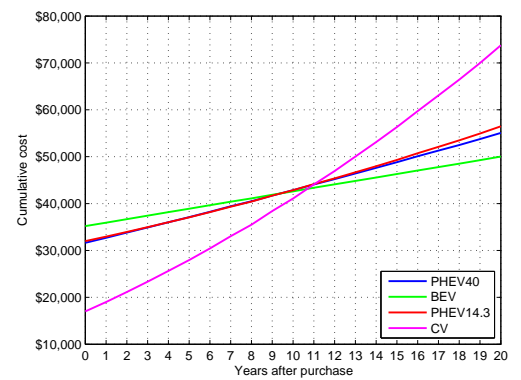

(a) Upward trend of fuel price

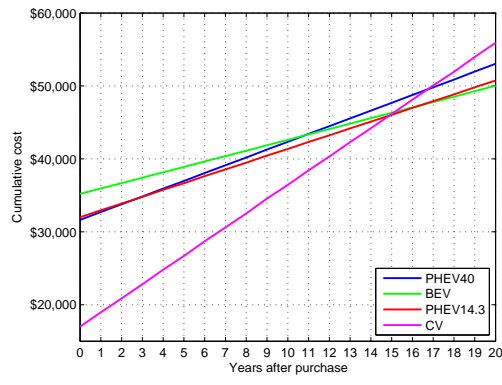

(b) Flat trend of fuel price

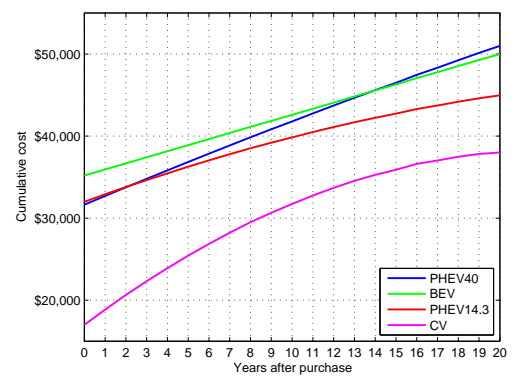

(c) Downward trend of fuel price

Figure 8: Cumulative vehicle plus energy (fuel \& electricity) costs

Table 2: Average gasoline consumption and gasoline displacement for an annual distance traveled of 13,820 miles

\begin{tabular}{lcccc}
\hline & PHEV $_{40}$ & PHEV $_{14.3}$ & BEV & CV \\
\hline Annual miles in gas mode & 2,103 & 8,700 & 0 & 13,820 \\
Annual miles in electric mode & 11,717 & 5,119 & 13,820 & 0 \\
Annual gasoline consumption & 60.1 gal & 170.6 gal & 0 gal & 530.7 gal \\
Annual gasoline displacement & $84.78 \%$ & $37.05 \%$ & $100 \%$ & $0 \%$ \\
\hline
\end{tabular}

gasoline price scenario, the higher the gasoline displacement the vehicle provides, the lower the energy cost incurred. In this sense, the BEV shows the lowest energy cost, followed by the PHEV 40 , the PHEV 14.3 , and the CV.

When analyzing the average annual gasoline consumption it was found that the gasoline displacement capability of an EV can lead to significant reduction in the cost of gasoline consumed. Table 2 summarizes the gasoline consumption, gasoline displacement and miles driven in electric and fuel mode by the different vehicles considered in our study. The average annual distance traveled by a user is 13,820 miles. Results show a BEV ability of full gasoline displacement (100\%) leads to an obvious null annual cost of gasoline. A PHEV 40 can provide $84.78 \%$ of gasoline displacement leading to saving up to $\$ 2,155$ in the annual cost of gasoline consumption compared to a CV. Finally the $\mathrm{PHEV}_{14.3}$ achieves a gasoline displacement of $37.05 \%$, with an annual saving up to $\$ 1,649$. The average annual cost in gasoline consumption registered for different gasoline price trends is shown in Table 3.

\subsubsection{Impact of different electricity pricing schemes}

Tables 4 and 5 summarize the annual electricity cost (US\$) and the cost per mile driven respectively for a vehicle owner under three different electricity pricing scenarios. From the results, it can be seen that TOU represents the most expensive option for a user, while RTP and the flat rate seem to be more economical compared with TOU. On average TOU is $24 \%$ more expensive than RTP and $19 \%$ more expensive than flat rate for any electrical vehicle.

Table 3: Average annual cost in gasoline consumption (in US\$)

\begin{tabular}{ccccc}
\hline Fuel price trend & PHEV $_{40}$ & PHEV $_{14.3}$ & BEV & CV \\
\hline $\boldsymbol{\lambda}$ & 275.4 & 781.4 & 0 & $2,430.7$ \\
$\boldsymbol{\searrow}$ & 220.0 & 624.6 & 0 & $1,942.8$ \\
& 165.0 & 467.7 & 0 & $1,454.6$ \\
\hline
\end{tabular}


Table 4: Average annual cost in electricity consumption (US\$)

\begin{tabular}{ccccc}
\hline Pricing scheme & PHEV $_{40}$ & PHEV $_{14.3}$ & BEV & CV \\
\hline Flat rate & 848.2 & 311.3 & 740.3 & 0.0 \\
TOU & 963.0 & 384.5 & 878.9 & 0.0 \\
RTP & 780.5 & 312.6 & 704.3 & 0.0 \\
\hline
\end{tabular}

Table 5: Cost per mile driven $(\$ /$ mile $)$

\begin{tabular}{cccccc}
\hline Pricing scheme & Fuel trend & PHEV $_{40}$ & PHEV $_{14.3}$ & BEV & CV \\
\hline Flat rate & & 0.0814 & 0.0792 & 0.0536 & 0.1761 \\
TOU & $\nearrow$ & 0.0924 & 0.0909 & 0.0637 & 0.1761 \\
RTP & & 0.0765 & 0.0792 & 0.051 & 0.1761 \\
\hline Flat rate & & 0.0774 & 0.0678 & 0.0536 & 0.1408 \\
TOU & $\rightarrow$ & 0.0857 & 0.0731 & 0.0637 & 0.1408 \\
RTP & & 0.0725 & 0.0679 & 0.051 & 0.1408 \\
\hline Flat rate & \multirow{}{*}{} & 0.0734 & 0.0564 & 0.0536 & 0.1054 \\
TOU & $\boldsymbol{}$ & 0.0817 & 0.0617 & 0.0637 & 0.1054 \\
RTP & & 0.0685 & 0.0565 & 0.051 & 0.1054 \\
\hline
\end{tabular}

The main reason for TOU to be the most expensive option is due to the high price it sets for the electricity at evening hours $(0.2788 \$ / \mathrm{kWh}$ between $1 \mathrm{pm}$ and $7 \mathrm{pm}$, see Figure 4$)$ when a user plugs his/her vehicle into the grid immediately when arriving at home after work, as assumed in this analysis. If the user postponed the charging of his/her vehicle after 9pm under TOU, when the off-peak time begins, a significant reduction in the cost of electricity consumption could be achieved. This could lead TOU to be a cheaper option.

The impact of TOU for a user can be quantified as an increase of $1 \Phi$ or $2 \mathbb{Q}$ in the cost per mile driven of an electrical vehicle when compared with other electricity pricing schemes depending on the trend of fuel price, as shown in Table 5. Generally speaking, it was found that the higher the gasoline displacement a vehicle can achieve, the lower the associated cost per mile driven for all fuel price trends. In this sense, a CV shows the highest cost per mile, while the BEV presents the lowest cost. The cost of driving a vehicle, in terms of the energy consumed, is lower for EVs (PHEVs and BEVs) in all scenarios, even when the price of fuel is expected to drop in the future. This support the statement suggesting that the total energy cost of EVs (fuel and electricity) is much lower than the energy cost of CVs (fuel only).

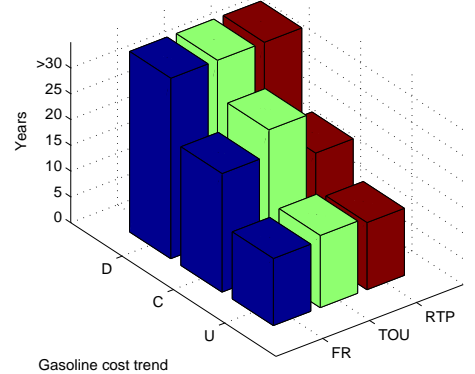

(a) $\mathrm{PHEV}_{40}$

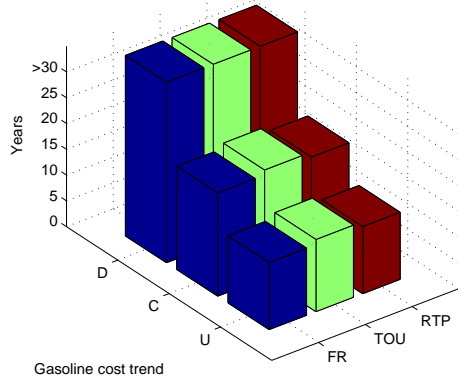

(b) PHEV $_{14.3}$

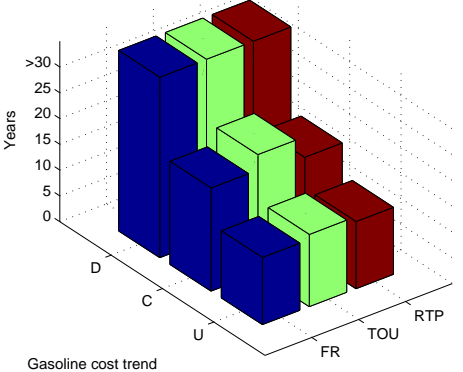

(c) BEV

Figure 9: Return on incremental premium as a function of fuel price trend and electricity pricing scheme 


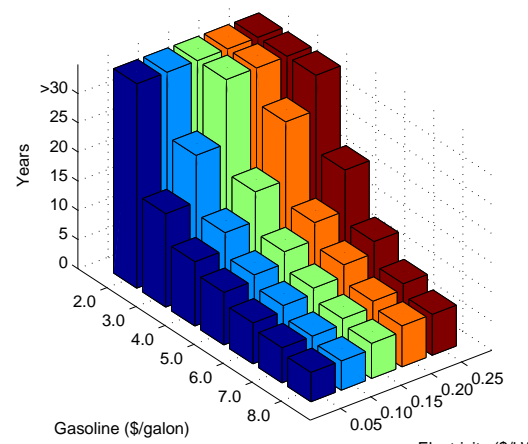

(a) $\mathrm{PHEV}_{40}$

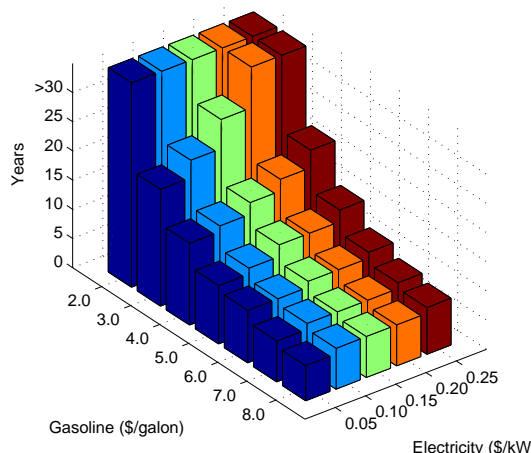

(b) $\mathrm{PHEV}_{14.3}$

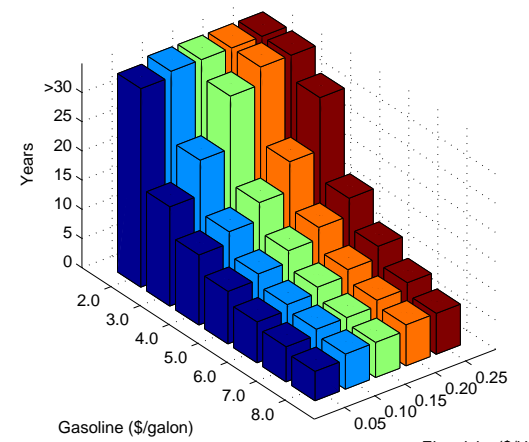

(c) $\mathrm{BEV}$

Figure 10: Return on incremental premium as a function of fixed fuel and electricity price

\subsubsection{Return on investment (ROI) for EVs}

The significantly higher retail cost and the lower driving and energy cost of an EV in comparison with a CV, motivates the analysis of return on investment for these vehicles. In our study we focus on the time required by a user to recover the incremental premium or the difference in retail cost with a CV in multiple scenarios of gasoline and electricity prices. Figure 9 shows the number of years required to recover the cost difference for multiple combinations of fuel cost trend and electricity pricing scheme for each type of EV. A constant annual inflation rate of $2.5 \%$ has been assumed, and that a vehicle's owner will not purchase a vehicle for more than 20 years. Thus, if the time required to recover the incremental premium is more than 20 years, it is assumed that it is not recoverable. From the figure it can be seen that fuel price trend has a significant impact on the time required to breakeven . For all EVs when the fuel price shows a downward trend, regardless the electricity pricing scheme considered, the incremental premium will never be recovered. For a flat trend of fuel cost, TOU increases the number of years to recover the incremental premium (28 years for a $\mathrm{PHEV}_{40}, 21$ years for a $\mathrm{PHEV}_{14.3}$, and 23 years for a BEV) compared with flat rate (23 years for a $\mathrm{PHEV}_{40}, 20$ years for a $\mathrm{PHEV}_{14.3}$, and 20 years for a BEV) and RTP (20 years for a $\mathrm{PHEV}_{40}, 20$ years for a $\mathrm{PHEV}_{14.3}$, and 19 years for a BEV). Finally, the upward trend of fuel price reduces the time it takes to recover the incremental premium for all EVs and also reduces the impact of different electricity pricing schemes. On average, in this scenario it takes between 13 to 14 years to recover the premium for all EVs under any electricity pricing scheme.

In order to analyze the return on investment as a function of gasoline and electricity prices, the study was conducted assuming a range of fixed prices for gasoline and electricity (flat rate) during the years of evaluation. A low gasoline and electricity price were assumed to be $\$ 2.0 /$ gallon and $\$ 0.05 / \mathrm{kWh}$ respectively, and a high gasoline and electricity price were $\$ 8.0 /$ gallon and $\$ 0.25 / \mathrm{kWh}$ respectively. Results are shown in Figure 10 .

The life expectancy of a modern vehicle in the US can be assumed to be around 150,000 miles (10-12 years) depending on maintenance. Therefore, in those scenarios in which return of incremental premium surpasses 10 years, EVs are unlikely to represent a real attractive economic option for a user. Assuming the current incremental 


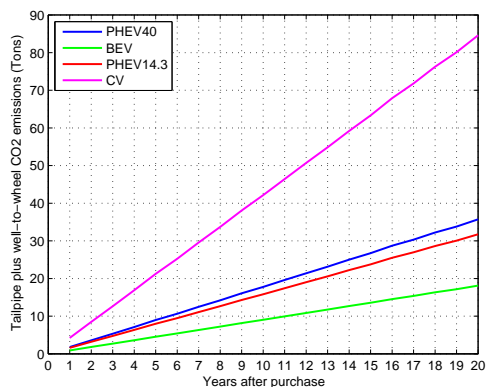

(a) Tailpipe and well-to-wheel $\mathrm{CO}_{2}$ emissions

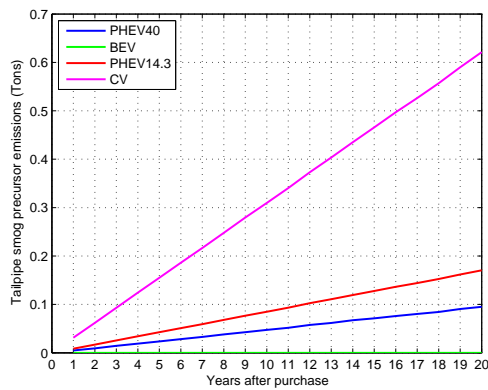

(b) Tailpipe air pollutant gases emission

Figure 11: Return on incremental premium as a function of fixed fuel and electricity price

premium of $\$ 15,000$, it is necessary for the fuel cost to rise to $\$ 5 /$ gallon and the electricity to be as low as $\$ 0.1 / \mathrm{kWh}$ in order to reduce the recovering time for any EV to 10 years. In the scenario of $\$ 8 /$ gallon of gasoline and the electricity cost of $\$ 0.15 / \mathrm{kWh}$, a $\mathrm{PHEV}_{40}$ or $\mathrm{BEV}$ owner requires 6 years to recover the incremental, whereas for a PHEV $_{14.3}$ owner it takes 7 years.

\subsubsection{Environmental impact: $\mathrm{CO}_{2}$ and pollutant gases emission}

The evaluation of environmental impact focused on the emission of GHG (carbon dioxide) and pollutant gases (nitrogen oxides, organic gases, etc) from the vehicles. GHG effects are global in nature since they are well mixed in the atmosphere in the long term; hence, the impact of a ton of $\mathrm{CO}_{2}$ to the environment is the same regardless where it is emitted. As a result, the analysis of $\mathrm{CO}_{2}$ emissions in this work considers tailpipe emissions and wellto-wheels emissions that includes emissions in power plants due to electricity generation to make the analysis more accurate. Figure 11(a) shows the cumulative $\mathrm{CO}_{2}$ emissions (tons) after years of purchasing the vehicle. The BEV can reduce $\mathrm{CO}_{2}$ emissions by $79 \%, \mathrm{PHEV}_{14.3}$ can reduce it by $62 \%$, and $\mathrm{PHEV}_{40}$ can reduce it by $57 \%$. The low carbon intensity generation mix of California, with a high fraction of natural gas and a low component of coal and petroleum, allows EVs to achieve a significant reduction in green house gas emission. Due to this generation mix the $\mathrm{PHEV}_{14.3}$ is able to achieve a higher reduction of total $\mathrm{CO}_{2}$ emissions compared with the $\mathrm{PHEV}_{40}$, despite, the latest can achieve a higher gasoline displacement and a higher tailpipe emission reduction. This shows how the real benefits of PHEVs in terms of environmental impact, depends on the carbon intensity in the power generation mix of a particular region.

Regarding smog precursor emissions, the impact of pollutant gases have a local nature, as they affect the area where they are emitted by creating toxic 'hot spots'. Thus, their analysis was limited to consider tailpipe emissions only. Results, shown in Figure 11(b), reveal that a $\mathrm{PHEV}_{40}$ can reduce emissions of pollutant gases by $85 \%$, the PHEV $_{14.3}$ by $75 \%$, and the BEV can fully avoid emissions reducing a $100 \%$ of them. 


\subsection{Going forward}

In this work, we have conducted an economic evaluation of PHEVs and EVs in comparison with ordinary CVs from a user's perspective. We have based our study on realistic specifications for vehicles currently available in the market and we have focused our analysis to the particular case study of California state. Our main analysis was oriented to examine the various factors such as energy cost, gasoline displacement, impact of dynamic electricity pricing schemes, investment recovery, and environmental benefits; in a user's decision to purchase an electrical vehicle. Findings from this work show that PHEVs and BEVs offer significant advantages over CVs in terms of reducing gasoline dependency, tailpipe green house and smog precursor gas emissions, and the energy cost to drive a vehicle. The cost of driving an EV is cheaper than the cost of driving a CV. Nevertheless, in order for an EV to become an attractive option for users with the current gasoline prices, there is a need to reduce the initial retail cost either by reducing manufacturing costs or by introducing subsidy policies. Since a significant proportion of costs are related to the battery, reducing the price of batteries is essential. The environmental advantages of PHEVs and EVs depend on the carbon intensity in generation mix. EVs can significantly reduce $\mathrm{CO}_{2}$ emissions where the electricity is derived from low carbon generation sources, otherwise total emissions can be as high (or even higher) than those for CVs. The impact of dynamic electricity pricing schemes on the economics of EVs is not as significant as the impact of gasoline or battery prices. Although, from our case study it was found that TOU pricing represents the most expensive option compared to RTP or flat rate pricing. Planned charging would be required in order to avoid the peak hours of TOU and reduce the electricity cost. On the contrary, RTP seems to be the cheapest option, and it is comparable with flat rate in most of the scenarios studied.

As part of our future work we are considering to include the following aspects:

- Define new case studies to include other geographical locations (e.g. India, China or Europe) with different driving patterns and sources of energy. This will allow us to contrast the results of the economic and environmental evaluation of EVs with our current case study.

- Consider further issues in the economic analysis, such as: subsidized EVs cost policy, different categories of vehicles targeting different segments, longer driving distance (in highways, not only in cities), variable inflation rates, etc. This will enable us to investigate new specific scenarios of interest.

- Evaluate the well-to-wheel cost of both electric and fossil energy used to power EVs and compare it with the cost involved to power CVs. This could allow to conduct an economic study from a governmental's perspective.

\subsection{Acknowledgment}

The authors would like to thank their colleagues at Toshiba Research Europe for helpful discussions and its Directors for their support of this work. 


\subsection{For further reading}

“Transportation's role in reducing US Greenhouse Gas emissions. Volume 1: Synthesis Report”. Report to Congress. US Department of Transportation. April, 2010.

A. Boulanger, A. Chu, S. Maxx, and D. Waltz, "Vehicle Electrification: Status and Issues". Proceedings of the IEEE, vol. 99, no. 6, pp. 1116-1138. June, 2011.

S. Borenstein, M. Jaske, and A. Rosenfeld, "Dynamic pricing, advanced metering, and demand response in electricity markets". Center for the Study of Energy Markets, University of California Energy Institute, 2002.

T. Carpenter, A. R. Curtis, and S. Keshav, "The Return On the Investment for Taxi Companies Trasitioning to Electric Vehicles: A case study in San Francisco". University of Waterloo, Tech. Rep. CS-2011-20, August 2011.

S. S. Raghavan and A. Khaligh, "Impact of Plug-in Hybrid Electric Vehicle charging on a distribution network in a Smart Grid environment". IEEE PES Innovative Smart Grid Technologies, pp. 1-7, January 2012.

\subsection{Biographies}

Raul Martinez Oviedo, Zhong Fan, Sedat Gormus, and Parag Kulkarni are with Toshiba Research Europe Ltd, Telecommunication Research Laboratory. 32 Queen Square, Bristol BS1 4ND, UK. Tel. +44 (0)117 9060700 , Fax. +44 (0)117 906 0701. (raul.martinez, zhong.fan, sedat.gormus, parag.kulkarni)@toshiba-trel.com 